\title{
Evaluation of the effects of prolotherapy on condyles in temporomandibular joint hypermobility using fractal dimension analysis
}

\author{
Sadi Memiş \\ Department of Oral and Maxillofacial Surgery, Faculty of Dentistry, Kocaeli University, Kocaeli, Turkey
}

\begin{abstract}
J Korean Assoc Oral Maxillofac Surg 2022;48:33-40)
Objectives: Prolotherapy is a method that has gained popularity in recent years and has been reported to have positive short-term and long-term clinical results in maxillofacial surgery, especially temporomandibular joint (TMJ) hypermobility. This study aimed to evaluate the changes in the trabecular structure of mandibular condyles in patients who underwent prolotherapy due to TMJ hypermobility using the fractal analysis method.

Materials and Methods: Forty-five patients who received dextrose prolotherapy at a concentration of $20 \%$ and fifteen control patients were included in the study. All patients had panoramic radiographs just before (T0) and six months after treatment (T1). The patients who received treatment were divided into three groups according to the number of prolotherapy injections. The regions of interest were selected from bone areas close to the articular surfaces of the condyles. The fractal dimension (FD) values were calculated.

Results: The main effect of time on the FD value was significant [F $(1,56)=86.176, P<0.001]$. This effect was qualified by a significant time $\times$ group interaction effect $[\mathrm{F}(3,56)=9.023, P<0.001]$. The decreases in $\mathrm{FD}$ values in all treatment groups between $\mathrm{T} 0$ and $\mathrm{T} 1$ times were significant $(P=0.004)$. However, changes in FD values were not significant in the control group $(P=0.728)$.

Conclusion: Dextrose prolotherapy without the effect of the number of injections caused a decrease in FD values in the mandibular condyles over time.
\end{abstract}

Key words: Dextrose, Fractals, Joint instability, Prolotherapy, Temporomandibular joint

[paper submitted 2021. 11. 6 / revised 2021. 12. 24 / accepted 2022. 1. 3]

\section{Introduction}

Temporomandibular joint (TMJ) hypermobility is defined as the hypertranslation of the mandibular condyle towards the anterior and superior aspects of the articular eminence as the mouth opens ${ }^{1}$. In the aetiology of TMJ hypermobility, factors such as the morphology of mandibular condyle, articular eminence and glenoid fossa, lateral pterygoid muscle activity, long anaesthesia intake, loss of tightness of joint ligaments, and trauma may play a role ${ }^{2}$.

TMJ hypermobility, which gives clinical symptoms such as pain, inability to perform mandibular movements, and open

\section{Sadi Memiş}

Department of Oral and Maxillofacial Surgery, Faculty of Dentistry, Kocaeli University, Yuvacik Campus, Pasadag M, Akcakesme S, No. 7, Kocaeli 41190, Turkey

TEL: +90-262-344-22-22

E-mail: sadimemis@gmail.com

ORCID: https://orcid.org/0000-0002-6551-1472

(c) This is an open-access article distributed under the terms of the Creative Commons Attribution Non-Commercial License (http://creativecommons.org/ licenses/by-nc/4.0/), which permits unrestricted non-commercial use, distribution, and reproduction in any medium, provided the original work is properly cited.

Copyright (C) 2022 The Korean Association of Oral and Maxillofacial Surgeons. locking, has various treatments, ranging from minimally invasive methods such as medication, Botox injection or intracapsular injection of sclerosed solutions, to advanced surgeries such as myotomy of the lateral pterygoid muscle ${ }^{1,3,4}$.

Prolotherapy is a method that has gained popularity in recent years and has been reported to have positive shortterm and long-term clinical results in maxillofacial surgery, especially TMJ hypermobility ${ }^{5,6}$. Prolotherapy, also called regenerative injection therapy or growth factor stimulation injection therapy, was first defined by Schultz in $1937^{1,7}$. Various non-pharmacological proliferants, such as glycerin, dextrose, and phenol, have been used for proliferation purposes ${ }^{8}$. Among these, dextrose is the most preferred. The mechanism of prolotherapy in TMJ has not been clearly defined. However, hypertonic dextrose applied to tendons and ligaments that have lost their flexibility for various reasons is considered to increase the repair process by affecting the non-inflammatory and inflammatory processes ${ }^{5,7}$. In the treatment of TMJ hypermobility, dextrose is used at concentrations of $10 \%-50 \%$ and in a single session or multiple sessions ${ }^{2,5,9}$. Most studies on this subject are clinically oriented. Studies showing the 
effect of prolotherapy on the hard tissue components of the joint are limited. The effect of prolotherapy using hypertonic dextrose on hard tissue can be examined by fractal dimension (FD) analysis.

FD analysis is a statistical method based on fractal mathematics used to describe complex shapes and structures ${ }^{10}$. Fractals consist of geometric shapes, such as curves, lines and points ${ }^{11}$. FD analysis is a proven and effective method for evaluating the microarchitecture structures of bones ${ }^{12}$. It has been confirmed to show early bone changes in the medical field ${ }^{13,14}$.

This study investigated FD change in the mandibular condyle in patients who had hypertonic dextrose prolotherapy for one, two, or three sessions due to TMJ hypermobility.

\section{Materials and Methods}

\section{Patients}

In this retrospective study, patients who received prolotherapy treatment from the author at Department of Oral and Maxillofacial Surgery of Bolu Abant Izzet Baysal University (Bolu, Turkey) between June 2017 and January 2020 were examined.

The inclusion criteria were one or more injections of bilateral dextrose prolotherapy due to TMJ hypermobility, having panoramic radiography taken before and six months after the end of the treatment, not having a previous operation in the TMJ area, no trauma history, and not having a systemic disease that could affect bone structure. Records of clinical examination findings and radiological examination were considered in the diagnosis of TMJ hypermobility. In all patients included, the TMJ radiographs taken before the procedure with the mouth open showed that the mandibular condyle was located beyond the articular eminence.

All patients except the control group received 20\% dextrose prolotherapy through at least one injection into the TMJ area. The patients received follow-up for at least six months. The patients were divided into three groups according to the number of prolotherapy injections they received; Group 1: one injection, Group 2: two injections, and Group 3: three injections. The control group was formed from patients with TMJ hypermobility who did not receive any treatment.

\section{Prolotherapy procedure}

The prolotherapy procedures applied to all patients were performed under local operating room conditions. A 27-gauge needle injector was used for each injection. The syringe to be applied to each addition was prepared as $3 \mathrm{~mL}$ dextrose solution ( $2 \mathrm{~mL}$ of $20 \%$ dextrose solution and 1:200,000 epinephrine with $1 \mathrm{~mL}$ of articaine). In the preauricular area, the skin surface was disinfected with povidone iodine solution. With reference to the cantal tragus line, the first entry point was 1 $\mathrm{cm}$ anterior and $2 \mathrm{~mm}$ inferior from the mid-tragus point; 1 $\mathrm{cm}$ below this point, the second entry point was marked with a surgical marker pen.(Fig. 1) The condyle was palpated by giving commands for mouth opening and closing to the patient. With the mouth open, $0.75 \mathrm{~mL}$ of solution was injected into the upper joint cavity from the upper entry point. Without removing the injector, it was directed upward, and the needle was removed by injecting $0.75 \mathrm{~mL}$ of solution into the area where the joint capsule was attached to the lateral margin of the glenoid fossa. The patient was instructed to close his/her mouth, and $0.75 \mathrm{~mL}$ of the solution was injected through the second needle entry located below, where the capsule was attached to the condyle neck from below. Then, the needle was directed superiorly, and $0.75 \mathrm{~mL}$ of the solution was injected into the surface of the TMJ capsule. The needle was then removed. The patients were advised to take paracetamol if they felt pain after the procedure. They were also instructed not to use different analgesics and anti-inflammatories to eliminate possible negative effects on prolotherapy.

The use of single or multiple injections of prolotherapy was decided based on the clinical findings of the patients, such as mouth opening measurements, pain status, and inability to

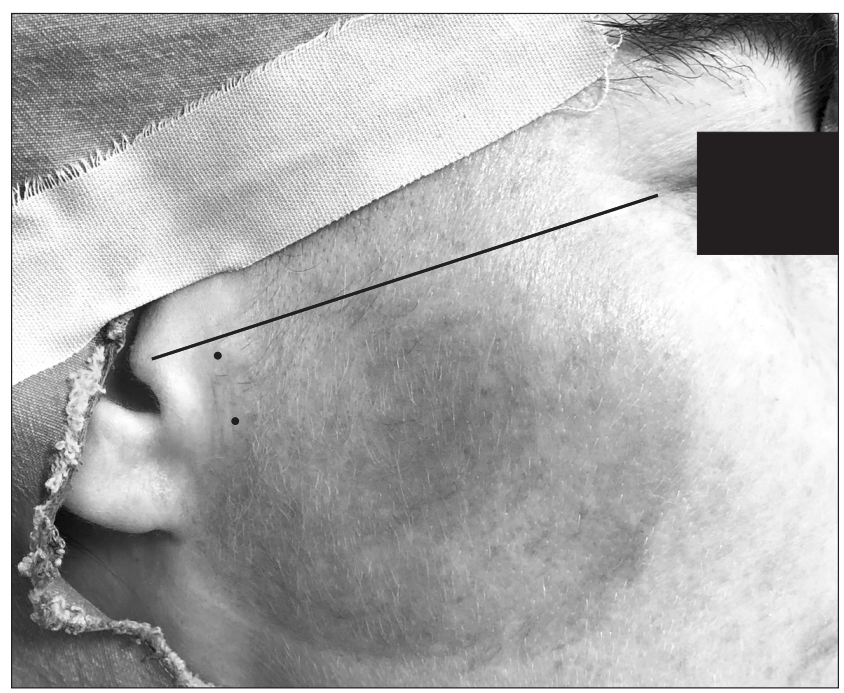

Fig. 1. Injection points for prolotherapy.

Sadi Memis: Evaluation of the effects of prolotherapy on condyles in temporomandibular joint hypermobility using fractal dimension analysis. J Korean Assoc Oral Maxillofac Surg 2022 
perform jaw movements comfortably. Prolotherapy was not performed again on the patients whose clinical complaints resolved. In patients who received more than one injection, an interval of six weeks was given between procedures.

\section{Radiography}

All patients' X-rays were obtained from the same archive All radiographs were taken using the same panoramic machine (Soredex; Cranex Novus, Tuusula, Finland) at $70 \mathrm{kVp}$ and $10 \mathrm{~mA}$ for an 8 seconds exposure time. The patients were positioned such that the Frankfurt plane was parallel to the floor and the sagittal plane was parallel to the vertical plane of the dental panoramic machine. All patients included in the study had panoramic radiographs taken before the procedure (T0) and six months after the procedure (T1).

\section{Fractal analysis}

The FD values were calculated for the right and left sides of the TMJ on each panoramic radiograph using the box counting method described by White and Rudolph ${ }^{15}$. The ImageJ version 1.53g (National Institutes of Health, Bethesda, MN, USA; http://rsb.info.nih.gov/nih-image) software was used for this process. Panoramic radiographs were opened using the ImageJ software. All containing bone tissue, the regions of interest (ROIs) with $50 \times 50$ pixels were selected from the mandibular condyles close to the articular surfaces.

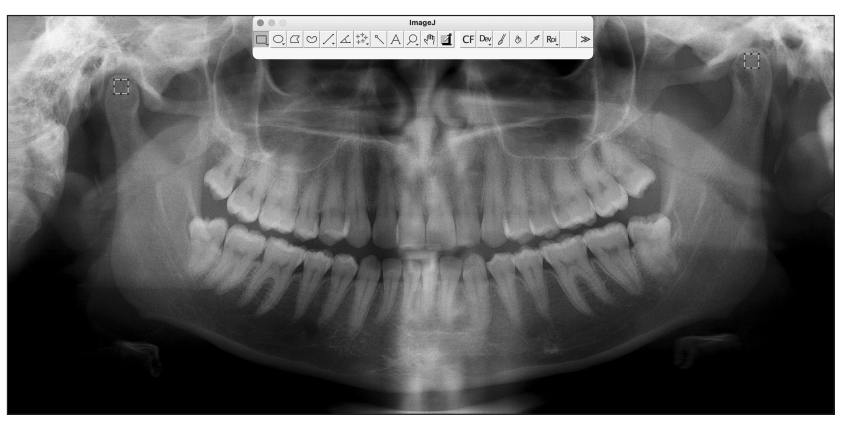

Fig. 2. Selection of regions of interest on the panoramic radiograph.

Sadi Memiss: Evaluation of the effects of prolotherapy on condyles in temporomandibular joint hypermobility using fractal dimension analysis. J Korean Assoc Oral Maxillofac Surg 2022

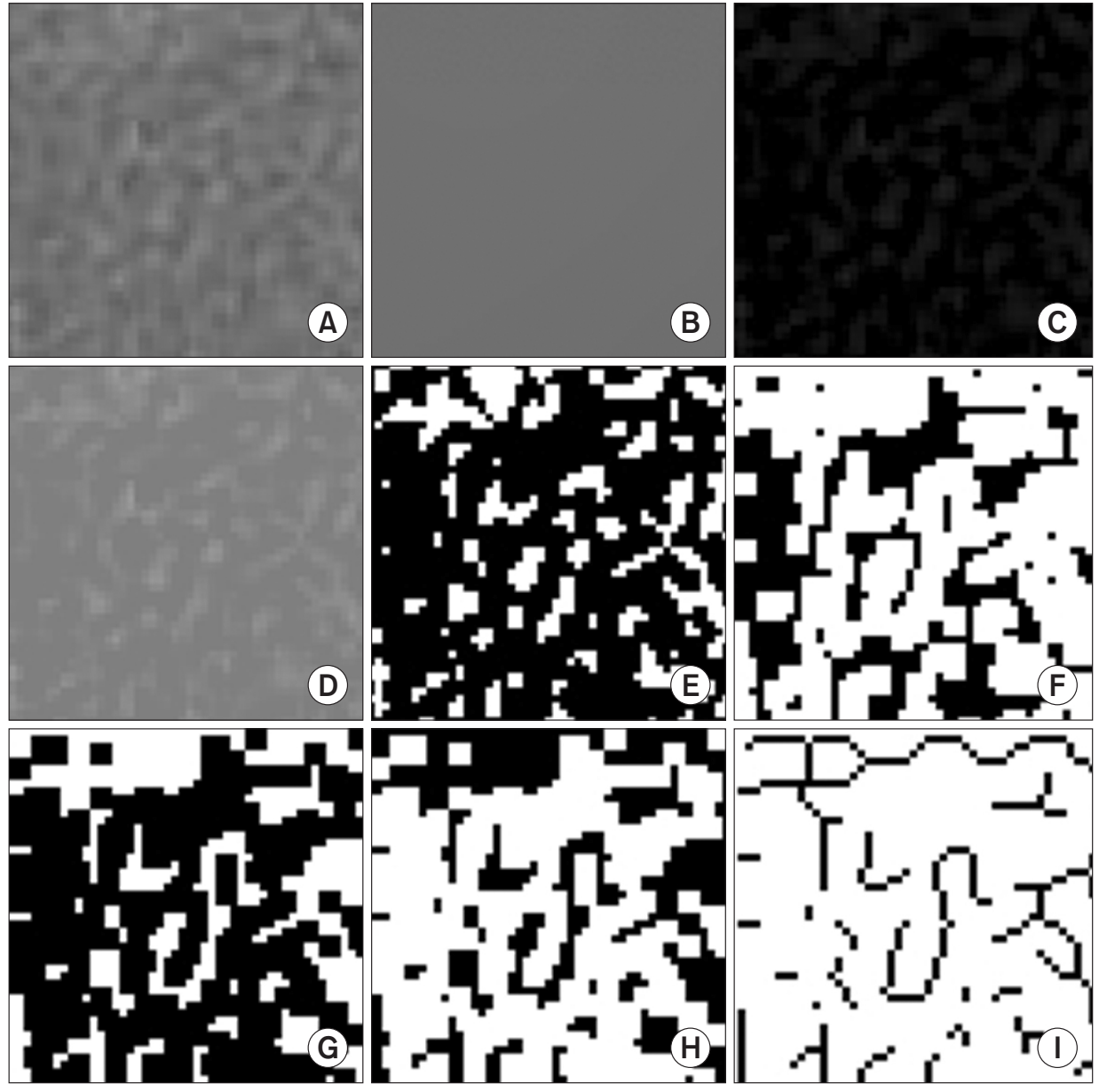

Fig. 3. Fractal dimension analysis process. A. Region of interest. B. Blurred image of the cropped and duplicated region of interest. C. Subtracted blurred image from the original image. D. Addition of a grey value of 128 to each pixel location. E. Binarization. F. Erosion. G. Dilatation. H. Inversion. I. Skeletonization.

Sadi Memis: Evaluation of the effects of prolotherapy on condyles in temporomandibular joint hypermobility using fractal dimension analysis. J Korean Assoc Oral Maxillofac Surg 2022 
(Fig. 2) The ROIs were duplicated. The image was blurred using the Gaussian filter. The blurry image was removed from the original image using the subtraction process. A total of 128 shades of grey were added to each pixel of the image. The image was turned into black and white using the threshold process, and erode, dilate, invert and skeletonization procedures were then applied to the image. Fractal box counting was performed in the resulting image.(Fig. 3) The FD values were calculated and recorded separately for panoramic radiographs taken at T0 and T1 times for both condyles of each patient.

All images were reviewed by the same researcher. The images of the patients were re-evaluated after 30 days to eliminate any errors and inconsistencies that may occur due to the researcher. Pearson correlation coefficients were calculated to determine the relationship between measures. As a result of the correlation analysis, there was no significant difference between the two measurements $(P>0.05)$.

\section{Statistical analysis}

As the data were distributed homogeneously according to the results of the Levene statistic test of homogeneity of variances, a two-way repeated measures ANOVA was used to evaluate the FDs. Gabriel's post hoc test was used for the paired comparison of differences between groups. The differences within groups were evaluated using a paired sample

Table 1. Fractal dimension measurements by group

\begin{tabular}{ccccc}
\hline \multicolumn{2}{c}{ Group } & Mean & SD & $\mathrm{n}$ \\
\hline Group 1 & RCFD T0 & 1.43418 & 0.079172 & 17 \\
& RCFD T1 & 1.41494 & 0.079887 & 17 \\
& LCFD T0 & 1.44106 & 0.055056 & 17 \\
Group 2 & LCFD T1 & 1.41918 & 0.061376 & 17 \\
& RCFD T0 & 1.44907 & 0.090673 & 15 \\
& RCFD T1 & 1.43080 & 0.099101 & 15 \\
& LCFD T0 & 1.43687 & 0.100270 & 15 \\
Group 3 & LCFD T1 & 1.40753 & 0.108682 & 15 \\
& RCFD T0 & 1.42338 & 0.101431 & 13 \\
& RCFD T1 & 1.39962 & 0.108183 & 13 \\
& LCFD T0 & 1.41346 & 0.089514 & 13 \\
Control & LCFD T1 & 1.39208 & 0.092639 & 13 \\
& RCFD T0 & 1.41220 & 0.073695 & 15 \\
& RCFD T1 & 1.41120 & 0.072264 & 15 \\
& LCFD T0 & 1.42433 & 0.063924 & 15 \\
& LCFD T1 & 1.42407 & 0.063880 & 15 \\
\hline
\end{tabular}

(SD: standard deviation, T0: before treatment, T1: six months after treatment, RCFD T0: fractal dimension value of right condyle at time T0, RCFD T1: fractal dimension value of right condyle at time T1, LCFD T0: fractal dimension value of left condyle at time T0, LCFD T1: fractal dimension value of left condyle at time T1)

Sadi Memiş: Evaluation of the effects of prolotherapy on condyles in temporomandibular joint hypermobility using fractal dimension analysis. J Korean Assoc Oral Maxillofac Surg 2022 $t$-test. The significance level was set to $P \leq 0.05$. Statistical analysis was performed using IBM SPSS Statistics software for Mac (ver. 25.0; IBM, Armonk, NY, USA).

\section{Results}

A total of 40 females and 20 males aged 18-68, with a mean of $30.95 \pm 12.38$ years, were included in the study. The number of patients in the groups was as follows: Group 1, $\mathrm{n}=17$; Group 2, $\mathrm{n}=15$; Group 3, $\mathrm{n}=13$, and the Control group, $\mathrm{n}=15$. The measurements by group are presented in Table 1 , considering the right and left sides.

There was no significant effect of sex on the FD variable $[\mathrm{F}(1,58)=0.766, P=0.385]$. The main effect of side on the FD value was not significant $[\mathrm{F}(1,56)=0.041, P=0.840]$. The effect of side $\times$ group interaction was not significant $[\mathrm{F}$ $(3,56)=0.440, P=0.726]$. The main effect of time on the FD value was significant $[\mathrm{F}(1,56)=86.176, P<0.001]$. This effect was qualified by a significant time $\times$ group interaction effect $[\mathrm{F}$ $(3,56)=9.023, P<0.001]$. The effect of side $\times$ time interaction effect was not significant $[\mathrm{F}(1,56)=0.740, P=0.393]$. The effect of side $\times$ time $\times$ group interaction was not significant $[\mathrm{F}(3$, 56) $=0.924, P=0.435]$. (Table 2 )

The main effect of the group on the mean FD value across time was not significant $[\mathrm{F}(3,56)=0.295, P=0.829]$. No significant difference was found between the pairwise comparisons of the groups $(P=0.947)$.(Table 3)

In addition, the within-group differences in all groups were evaluated at T0 and T1 times using the paired $t$-test. The decreases in FD values in treatment groups between $\mathrm{T} 0$ and $\mathrm{T} 1$ times were significant $(P=0.004)$. However, changes in FD values were not significant in the control group $(P=0.728)$. (Table 4)

The means of the FD values at T0 and T1 times are plotted graphically in Fig. 4 and 5.

Table 2. Results of two-way repeated measures ANOVA

\begin{tabular}{lcc}
\hline \multicolumn{1}{c}{ Interaction } & \multicolumn{1}{c}{$\mathrm{F}$} & $P$-value \\
\hline Side & 0.041 & 0.840 \\
Sidexgroup & 0.440 & 0.726 \\
Time & 86.176 & $0.000^{*}$ \\
Timexgroup & 9.023 & $0.000^{*}$ \\
Sidextime & 0.740 & 0.393 \\
Sidextimexgroup & 0.924 & 0.435 \\
\hline
\end{tabular}

$(\times$ : interaction)

$* P \leq 0.05$

By ANOVA, Greenhouse-Geisser correction.

Sadi Memiş: Evaluation of the effects of prolotherapy on condyles in temporomandibular joint hypermobility using fractal dimension analysis. J Korean Assoc Oral Maxillofac Surg 2022 
Table 3. Results of multiple comparisons

\begin{tabular}{llccr}
\hline Group (I) & Group (J) & $\begin{array}{c}\text { Mean } \\
\text { difference (I-J) }\end{array}$ & SE & $P$-value \\
\hline Group 1 & Group 2 & -0.00373 & 0.026144 & $>0.999$ \\
& Group 3 & 0.02020 & 0.027191 & 0.973 \\
& Control & 0.00939 & 0.026144 & 0.999 \\
Group 2 & Group 1 & 0.00373 & 0.026144 & $>0.999$ \\
& Group 3 & 0.02393 & 0.027966 & 0.947 \\
& Control & 0.01312 & 0.026948 & 0.997 \\
Group 3 & Group 1 & -0.02020 & 0.027191 & 0.973 \\
& Group 2 & -0.02393 & 0.027966 & 0.947 \\
Control & Control & -0.01082 & 0.027966 & 0.999 \\
& Group 1 & -0.00939 & 0.026144 & 0.999 \\
& Group 2 & -0.01312 & 0.026948 & 0.997 \\
& Group 3 & 0.01082 & 0.027966 & 0.999 \\
\hline
\end{tabular}

(SE: standard error)

Based on observed means.

The error term is mean square (error) $=0.005$.

By Gabriel's post hoc test.

Sadi Memiş: Evaluation of the effects of prolotherapy on condyles in temporomandibular joint hypermobility using fractal dimension analysis. J Korean Assoc Oral Maxillofac Surg 2022

Table 4. Results of evaluating the within-group differences between two different times

\begin{tabular}{llccc}
\hline & Group & Mean & SE & $P$-value \\
\hline \multirow{2}{*}{ Group 1 } & RCFD T0-RCFD T1 & 0.019235 & 0.005102 & $0.002^{*}$ \\
& LCFD T0-LCFD T1 & 0.021882 & 0.004013 & $0.000^{*}$ \\
Group 2 & RCFD T0-RCFD T1 & 0.018267 & 0.005321 & $0.004^{*}$ \\
& LCFD T0-LCFD T1 & 0.029333 & 0.006657 & $0.001^{*}$ \\
Group 3 & RCFD T0-RCFD T1 & 0.023769 & 0.006634 & $0.004^{*}$ \\
& LCFD T0-LCFD T1 & 0.021385 & 0.004474 & $0.000^{*}$ \\
Control & RCFD T0-RCFD T1 & 0.000467 & 0.001316 & 0.728 \\
& LCFD T0-LCFD T1 & -0.000267 & 0.001449 & 0.857 \\
\hline
\end{tabular}

(SE: standard error, T0: before treatment, T1: six months after treatment, RCFD T0: fractal dimension value of right condyle at time T0, RCFD T1: fractal dimension value of right condyle at time T1, LCFD T0: fractal dimension value of left condyle at time T0, LCFD T1: fractal dimension value of left condyle at time T1)

$* P \leq 0.05$

By paired $t$-test.

Sadi Memis: Evaluation of the effects of prolotherapy on condyles in temporomandibular joint hypermobility using fractal dimension analysis. J Korean Assoc Oral Maxillofac Surg 2022

\section{Discussion}

In patients with bilateral TMJ hypermobility, the FD values calculated in the mandibular condyles of patients who received hypertonic dextrose prolotherapy decreased depending on time $(P<0.001)$. No interactions of the decrease in FD values with side, number of injections, or sex were found. FD analysis has been used previously to evaluate bone healing after endodontic surgery, orthognathic surgery, and implant treatments and to evaluate bone structures in TMJ disorders ${ }^{11,16-20}$. Higher FD values indicate more complex structures. However, structures with the same FD value may not show the same texture feature ${ }^{10,21}$. FD value reduction in

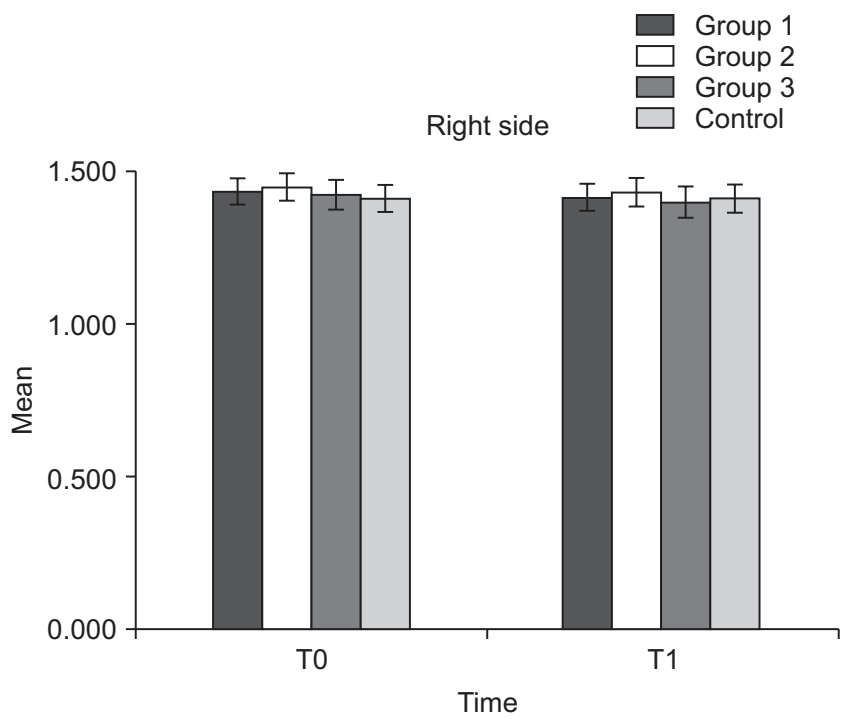

Fig. 4. Distribution of the fractal dimension values of the right-sided condyles. (TO: before treatment, T1: six months after treatment) Sadi Memiş: Evaluation of the effects of prolotherapy on condyles in temporomandibular joint hypermobility using fractal dimension analysis. J Korean Assoc Oral Maxillofac Surg 2022

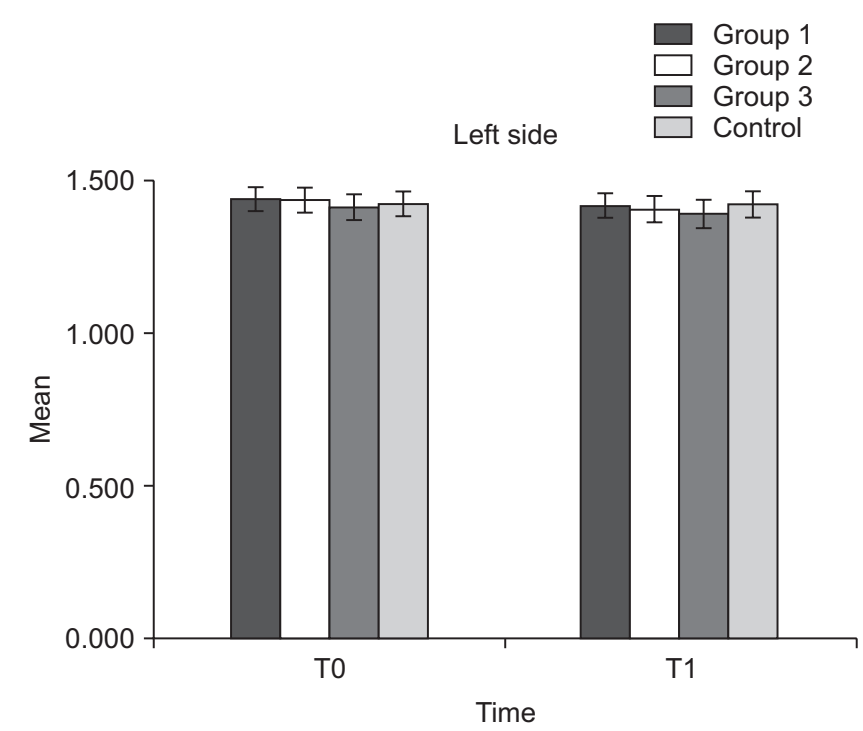

Fig. 5. Distribution of the fractal dimension values of the left-sided condyles. (TO: before treatment, T1: six months after treatment) Sadi Memiss: Evaluation of the effects of prolotherapy on condyles in temporomandibular joint hypermobility using fractal dimension analysis. J Korean Assoc Oral Maxillofac Surg 2022

surgical sites is associated with decreased bone complexity. Arsan et al. ${ }^{11}$ reported that erosive and sclerotic changes in the condyle in TMJ patients could be seen as a decrease in FD values.

Various proliferants are used in prolotherapy. Dextrose is the most widely used proliferant because it is inexpensive, accessible, and reliable. The techniques used in the treatment of TMJ hypermobility and dysfunction with the purpose of 
prolotherapy with a single injection or multiple injections and using dextrose in different concentrations have been described $^{5,6,9,22}$. There is no definite protocol for prolotherapy in TMJ hypermobility. Dextrose concentrations used in prolotherapy range from $10 \%$ to $50 \% \%^{2,6,9,22-24}$. In this study, dextrose at a concentration of $20 \%$, which gives positive clinical results on TMJ hypermobility in the literature, was used, and positive clinical results were obtained for all patients ${ }^{25,26}$.

Although the mechanism of prolotherapy has not been fully discovered, it is believed that its inflammatory and noninflammatory mechanisms play a role ${ }^{9}$. Dextrose in concentrations above $10 \%$ is known to cause partial inflammation ${ }^{1,9}$. In histopathological examinations performed after a dextrose injection, first-day hemorrhage, inflammation and necrosis in the soft tissues and ligaments were reported, followed by fibrosis, repair tissue, and regeneration symptoms ${ }^{9,27}$. Histopathologically, the strengthening and thickening of the tendons and ligaments were demonstrated after prolotherapy ${ }^{28}$. Studies on changes in hard tissues are limited. There is a need for histopathological studies on the effect of inflammation after prolotherapy and subsequent regeneration of the hard tissue components of the joint at different concentrations and numbers of injections.

Studies on prolotherapy in TMJ have generally focused on clinical findings, such as pain, maximal interincisal opening (MIO), locking episode frequency, and sound in $\mathrm{TMJ}^{6,29}$. Studies have reported different results on clinical findings after prolotherapy in TMJ hypermobility patients. Ungor et al. ${ }^{6}$ reported a decrease in pain on function after prolotherapy in patients with TMJ dislocation. Taskesen and Cezairli ${ }^{29}$ found a reduction in pain after prolotherapy in patients with TMJ hypermobility. Cömert Kiliç and Güngörmüş ${ }^{2}$ reported that prolotherapy caused a decrease in MIO in TMJ hypermobility, but there was no difference in the placebo group in other clinical findings, such as joint noise and pain.

Unlike other studies, this study evaluated the change in the trabecular structure in the long-term areas of the condyles close to the articular surface after prolotherapy using the FD analysis method. There was a decrease in the obtained $\mathrm{FD}$ values at $\mathrm{T} 1$ time compared with $\mathrm{T} 0$ time. This can be interpreted as the inflammation that occurs in this area and affecting the hard tissues over a period of six months. Longer follow-up studies are recommended at dextrose concentrations different from those used in this study.

In the literature review, dextrose prolotherapy is mostly performed as three or four injections in $\mathrm{TMJ}^{5,6,30}$. In some studies, prolotherapy was performed as a single injection in the TMJ and obtained positive results ${ }^{7,9,25}$. In the current study, three groups of patients who received positive clinical results after one injection, two injections, and three injections of prolotherapy were formed, and their results were compared. The number of injections was found to have no effect on the change in FD value in the condyles when dextrose was used at a concentration of $20 \%$. However, to relieve the clinical symptoms of patients, re-injection/injections are required.

Prolotherapy is widely used, especially in diseases of the musculoskeletal system. Prolotherapy, which is used in the regeneration of ligaments and tendons, has also been reported to provide effective results in osteoarthritis ${ }^{24,28,31}$. In a disease such as osteoarthritis in which bone tissue is affected, the effectiveness of dextrose suggests that it may also affect hard tissues. During prolotherapy application, not only intra-articular injection but also injection around the joint may affect the hard tissue. Due to the slower regeneration times of hard tissues compared with soft tissues, a decrease in FD value in bone may be observed in the sixth month.

The changes in FD values observed in the treatment groups may not indicate large structural changes. Since the jaw movements and muscle functions of the patients in the treatment groups may change after the treatment, FD changes can be considered not only as a result of dextrose injections, but also as an adaptation response in the condyles to these mechanical changes. The fact that FD changes were not significant in the control group may be attributed to the absence of changes in the TMJ movements and chewing mechanisms of the patients.

\section{Conclusion}

After dextrose prolotherapy was applied to patients with hypermobility in the TMJ, the FD values in the areas close to the articular surface of the condyles decreased depending on time. Studies with different dextrose concentrations and longer follow-ups are recommended.

\section{Author's Contributions}

S.M. participated in design of study, analysis, and drafting the manuscript.

\section{Ethics Approval and Consent to Participate}

The study was approved by the Kocaeli University Ethical Committee of Non-Invasive Clinical Research (Institutional 
Review Board No. 2020/293). Patient consent was not required because of the retrospective nature of the study. The guidelines of the Declaration of Helsinki were followed in this study.

\section{Conflict of Interest}

No potential conflict of interest relevant to this article was reported.

\section{References}

1. Refai H, Altahhan O, Elsharkawy R. The efficacy of dextrose prolotherapy for temporomandibular joint hypermobility: a preliminary prospective, randomized, double-blind, placebo-controlled clinical trial. J Oral Maxillofac Surg 2011;69:2962-70. https://doi. org/10.1016/j.joms.2011.02.128

2. Cömert Kiliç S, Güngörmüş M. Is dextrose prolotherapy superior to placebo for the treatment of temporomandibular joint hypermobility? A randomized clinical trial. Int J Oral Maxillofac Surg 2016; 45:813-9. https://doi.org/10.1016/j.ijom.2016.01.006

3. Albilia JB, Weisleder H, Wolford LM. Treatment of posterior dislocation of the mandibular condyle with the double Mitek mini anchor technique: a case report. J Oral Maxillofac Surg 2018;76:396. e1-9. https://doi.org/10.1016/j.joms.2017.09.017

4. Agbara R, Fomete B, Obiadazie AC, Idehen K, Okeke U. Temporomandibular joint dislocation: experiences from Zaria, Nigeria J Korean Assoc Oral Maxillofac Surg 2014;40:111-6. https://doi. org/10.5125/jkaoms.2014.40.3.111

5. Refai H. Long-term therapeutic effects of dextrose prolotherapy in patients with hypermobility of the temporomandibular joint: a single-arm study with 1-4 years' follow up. Br J Oral Maxillofac Surg 2017;55:465-70. https://doi.org/10.1016/j.bjoms.2016.12.002

6. Ungor C, Atasoy KT, Taskesen F, Cezairli B, Dayisoylu EH, Tosun E, et al. Short-term results of prolotherapy in the management of temporomandibular joint dislocation. J Craniofac Surg 2013;24: 411-5. https://doi.org/10.1097/SCS.0b013e31827ff14f

7. Majumdar SK, Krishna S, Chatterjee A, Chakraborty R, Ansari N. Single injection technique prolotherapy for hypermobility disorders of TMJ using $25 \%$ dextrose: a clinical study. J Maxillofac Oral Surg 2017;16:226-30. https://doi.org/10.1007/s12663-016-0944-0

8. Klein RG, Eek BC, DeLong WB, Mooney V. A randomized double-blind trial of dextrose-glycerine-phenol injections for chronic, low back pain. J Spinal Disord 1993;6:23-33.

9. Zhou H, Hu K, Ding Y. Modified dextrose prolotherapy for recurrent temporomandibular joint dislocation. Br J Oral Maxillofac Surg 2014;52:63-6. https://doi.org/10.1016/j.bjoms.2013.08.018

10. Demirbaş AK, Ergün S, Güneri P, Aktener BO, Boyacioğlu H. Mandibular bone changes in sickle cell anemia: fractal analysis. Oral Surg Oral Med Oral Pathol Oral Radiol Endod 2008;106:e418. https://doi.org/10.1016/j.tripleo.2008.03.007

11. Arsan B, Köse TE, Çene E, Özcan İ. Assessment of the trabecular structure of mandibular condyles in patients with temporomandibular disorders using fractal analysis. Oral Surg Oral Med Oral Pathol Oral Radiol 2017;123:382-91. https://doi.org/10.1016/ j.00oo.2016.11.005

12. Kurşun-Çakmak EŞ, Bayrak S. Comparison of fractal dimension analysis and panoramic-based radiomorphometric indices in the assessment of mandibular bone changes in patients with type 1 and type 2 diabetes mellitus. Oral Surg Oral Med Oral Pathol Oral Radiol 2018;126:184-91. https://doi.org/10.1016/j.oooo.2018.04.010

13. Aktuna Belgin $\mathrm{C}$, Serindere G. Fractal and radiomorphometric analysis of mandibular bone changes in patients undergoing intravenous corticosteroid therapy. Oral Surg Oral Med Oral Pathol Oral Radiol 2020;130:110-5. https://doi.org/10.1016/j.oooo.2019.12.009

14. Bayrak S, Göller Bulut D, Orhan K, Sinanoğlu EA, Kurşun Çakmak EŞ, Mısırlı M, et al. Evaluation of osseous changes in dental panoramic radiography of thalassemia patients using mandibular indexes and fractal size analysis. Oral Radiol 2020;36:18-24. https://doi.org/10.1007/s11282-019-00372-7

15. White SC, Rudolph DJ. Alterations of the trabecular pattern of the jaws in patients with osteoporosis. Oral Surg Oral Med Oral Pathol Oral Radiol Endod 1999;88:628-35. https://doi.org/10.1016/s10792104(99)70097-1

16. Uğur Aydın Z, Toptaş O, Göller Bulut D, Akay N, Kara T, Akbulut N. Effects of root-end filling on the fractal dimension of the periapical bone after periapical surgery: retrospective study. Clin Oral Investig 2019;23:3645-51. https://doi.org/10.1007/s00784-01902967-0

17. Heo MS, Park KS, Lee SS, Choi SC, Koak JY, Heo SJ, et al. Fractal analysis of mandibular bony healing after orthognathic surgery. Oral Surg Oral Med Oral Pathol Oral Radiol Endod 2002;94:7637. https://doi.org/10.1067/moe.2002.128972

18. Suer BT, Yaman Z, Buyuksarac B. Correlation of fractal dimension values with implant insertion torque and resonance frequency values at implant recipient sites. Int J Oral Maxillofac Implants 2016; 31:55-62. https://doi.org/10.11607/jomi.3965

19. Wilding RJ, Slabbert JC, Kathree H, Owen CP, Crombie K, Delport P. The use of fractal analysis to reveal remodelling in human alveolar bone following the placement of dental implants. Arch Oral Biol 1995;40:61-72. https://doi.org/10.1016/0003-9969(94)001382

20. Zeytinoğlu M, İlhan B, Dündar N, Boyacioğlu H. Fractal analysis for the assessment of trabecular peri-implant alveolar bone using panoramic radiographs. Clin Oral Investig 2015;19:519-24. https:// doi.org/10.1007/s00784-014-1245-y

21. Yasar F, Akgünlü F. Fractal dimension and lacunarity analysis of dental radiographs. Dentomaxillofac Radiol 2005;34:261-7. https:// doi.org/10.1259/dmfr/85149245

22. Priyadarshini S, Gnanam A, Sasikala B, Elavenil P, Raja Sethupathy Cheeman S, Mrunalini R, et al. Evaluation of prolotherapy in comparison with occlusal splints in treating internal derangement of the temporomandibular joint - a randomized controlled trial. J Craniomaxillofac Surg 2021;49:24-8. https://doi.org/10.1016/ j.jcms.2020.11.004

23. Louw WF, Reeves KD, Lam SKH, Cheng AL, Rabago D. Treatment of temporomandibular dysfunction with hypertonic dextrose injection (prolotherapy): a randomized controlled trial with longterm partial crossover. Mayo Clin Proc 2019;94:820-32. https://doi. org/10.1016/j.mayocp.2018.07.023

24. Fouda AA. Change of site of intra-articular injection of hypertonic dextrose resulted in different effects of treatment. Br J Oral Maxillofac Surg 2018;56:715-8. https://doi.org/10.1016/ j.bjoms.2018.07.022

25. Abdullakutty A, Sidebottom A. Is dextrose prolotherapy effective in managing recurrent temporomandibular joint (TMJ) dislocations - a prospective study. Br J Oral Maxillofac Surg 2018;56:e93-4. https://doi.org/10.1016/j.bjoms.2018.10.261

26. Mustafa R, Güngörmüş M, Mollaoğlu N. Evaluation of the efficacy of different concentrations of dextrose prolotherapy in temporomandibular joint hypermobility treatment. J Craniofac Surg 2018;29:e461-5. https://doi.org/10.1097/SCS.0000000000004480

27. Dagenais S, Wooley J, Hite M, Green R, Mayer J. Acute toxicity evaluation of proliferol: a dose-escalating, placebo-controlled study in swine. Int J Toxicol 2009;28:219-29. https://doi. org/10.1177/1091581809336478

28. Rabago D, Mundt M, Zgierska A, Grettie J. Hypertonic dextrose injection (prolotherapy) for knee osteoarthritis: long term outcomes. Complement Ther Med 2015;23:388-95. https://doi. 
org/10.1016/j.ctim.2015.04.003

29. Taşkesen F, Cezairli B. Efficacy of prolotherapy and arthrocentesis in management of temporomandibular joint hypermobility. Cranio 2020. https://doi.org/10.1080/08869634.2020.1861887 [Epub ahead of print]

30. Hakala RV, Ledermann KM. The use of prolotherapy for temporomandibular joint dysfunction. J Prolotherapy 2010;2:439-46.

31. Kim SR, Stitik TP, Foye PM, Greenwald BD, Campagnolo DI. Critical review of prolotherapy for osteoarthritis, low back pain, and other musculoskeletal conditions: a physiatric perspective. Am J Phys Med Rehabil 2004;83:379-89. https://doi.org/10.1097/01.

$$
\text { phm.0000124443.31707.74 }
$$

How to cite this article: Memiş S. Evaluation of the effects of prolotherapy on condyles in temporomandibular joint hypermobility using fractal dimension analysis. J Korean Assoc Oral Maxillofac Surg 2022;48:33-40. https://doi.org/10.5125/ jkaoms.2022.48.1.33 